\title{
REVIEW
}

\section{Advanced paternal age and reproductive outcome}

\author{
Zofnat Wiener-Megnazi, Ron Auslender and Martha Dirnfeld
}

Women have been increasingly delaying the start of motherhood in recent decades. The same trend is seen also for men. The influence of maternal age on fertility, chromosomal anomalies, pregnancy complications, and impaired perinatal and post-natal outcome of offspring, has been thoroughly investigated, and these aspects are clinically applied during fertility and pregestational counseling. Male aging and reproductive outcome has gained relatively less attention. The purpose of this review is to evaluate updated and relevant literature on the effect of paternal age on reproductive outcome.

Asian Journal of Andrology (2012) 14,69-76; doi:10.1038/aja.2011.69; published online 12 December 2011

Keywords: ART outcomes; fertility; male aging; paternal age; reproductive outcome

\section{INTRODUCTION}

The rise in life expectancy, women's entry into the labor market and the popular use of contraception, have contributed to the social phenomena of delaying family planning and parenthood to the mid or late thirties.

Assisted reproductive technologies have become more accessible to the general population, enabling older couples to hope that they can materialize their aspirations for healthy offspring later in life. It is well established that the main limiting factor to fertility and good reproductive outcome has been female's age. ${ }^{1,2}$

The trend of older parenthood is true also for males. In Germany, the median age of married fathers has increased from 31.3 years in 1991 to 33.1 years in $1999 .{ }^{3}$ The same trend has also been observed in England. In 1993, fathers aged 35-54 years accounted for $25 \%$ of live births. Ten years later, these percentages grew to $40 \%{ }^{4}$ (Figure 1). Therefore, attention should also be paid to the influence of advanced paternal age on reproductive outcome. In this review, we have extensively investigated the present data on male age-related effects on sexuality, testicular function, sperm parameters, risk of chromosomal disorders, specific genetic mutations, epigenetic changes, multifactorial disorders and perinatal outcome.

Testicular function and spermatogenesis

In contrast to menopause, which marks the cessation of ovarian function due to the inevitable loss of female gametes, spermatogenesis continues throughout life. ${ }^{5}$ Nevertheless, male aging does exert a certain detrimental effect on reproductive organs and tissues. These reported changes develop gradually without a sudden age threshold. Testicular volume decreases only towards the eighth decade ${ }^{6}$ and in healthy men, it is $31 \%$ lower than in the 18 - to 40 -year age group. This change is accompanied by alterations in testicular histomorphology observed in older men. ${ }^{7,8}$ In a multivariate analysis, follicle-stimulating hormone (FSH), inhibin B and testosterone were independently associated with bilateral testicular volume in the elderly. This moderately decreased bilateral testicular volume observed in elderly men was strongly associated with a decrease in the inhibin $\mathrm{B} / \mathrm{FSH}$ ratio, and was consistent with a reduced Sertoli cell mass, compensated by increased FSH stimulation resulting in only limited decrease of Sertoli cell function. ${ }^{9}$ FSH increases slightly in men between 40 and 70 years. ${ }^{10,11}$ This is concomitant with a decrease in inhibin $\mathrm{B}$ and an increase in activin A. ${ }^{10}$ In addition, the decrease in Leydig cell function yields in an agerelated reduction in testosterone levels, ${ }^{8,10}$ starting at the age of 30 years. ${ }^{12}$ The manifestations include decreased bone and muscle mass, sexual body hair and beard growth, and increased abdominal obesity, as well as higher incidence of erectile dysfunction, which increases to $>30 \%-40 \%$ in the eighth decade. ${ }^{7,12,13}$ Age-related erectile dysfunction has also been associated with endothelial dysfunction due to atherosclerosis of the penile arteries and a reduction in the production of nitric oxide. ${ }^{7}$ In a retrospective study of 3698 infertile patients, the incidence of infection in the accessory glands increased from $6.1 \%$ among males aged $<25$ years to $13.6 \%$ of patients aged $>40$ years, and total sperm count was lower $(P<0.0001) .{ }^{14}$ Numerous studies have examined the age-related effect on semen characteristics. ${ }^{3}$ There is a trend of age-related decline in daily sperm production per testis. ${ }^{6}$ Semen volume and motility (evaluated both qualitatively and by computer-assisted sperm analysis method), tend to decrease with age. ${ }^{15,16}$

In some studies, a paternal age-related decline in semen characteristics was not observed, but this is probably due to relative small numbers of older-aged men in the study population. One of the proposed mechanisms for the age-related decrease in testicular function is a change in the production of reactive oxygen species by Leydig cells mitochondria. ${ }^{12}$ Oxidative potential in seminal plasma (measured by the thermocheniluminescence assay) from 148 men undergoing semen analysis exhibited ${ }^{17}$ was inversely correlated with patients' age (Lissak et al, 2004, unpublished data).

REPRODUCTIVE OUTCOME IN IN VITRO FERTILIZATION (IVF) Age-related decline in testicular function could be overcome by the use of IVF-intracytoplasmic sperm injection techniques in terms of 

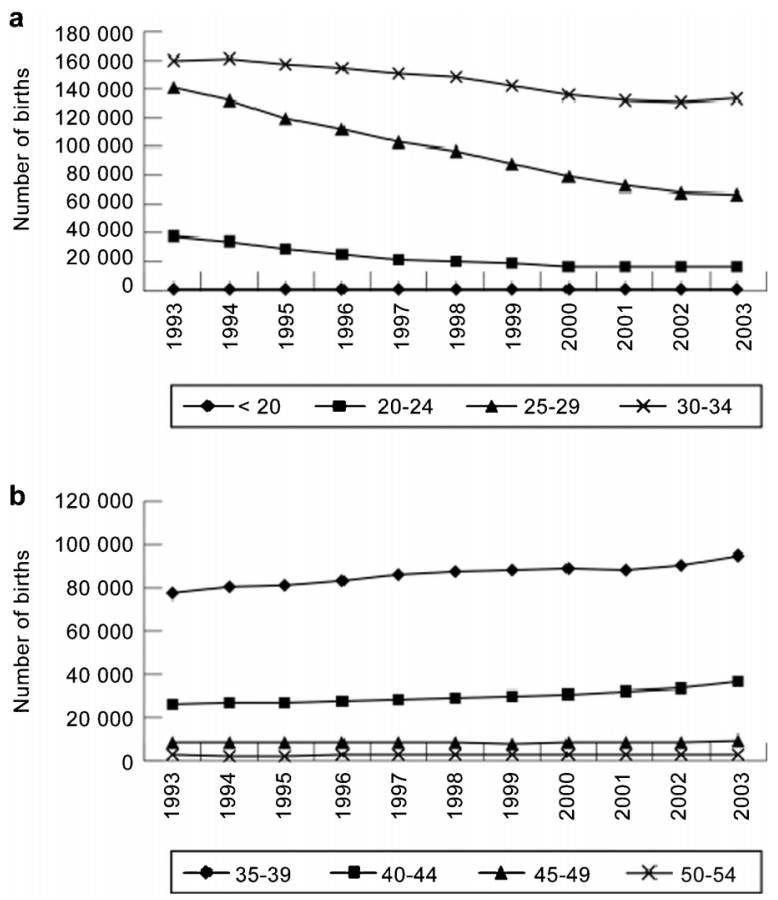

Figure 1 Trends in paternal age for live births within marriage in England and Wales, 1993-2003: (a) decreasing trends ( $<35$ years); (b) increasing trends (35-54 years). Source: Birth Statistics, England and Wales, Series FM1 no. 32 (Office for National Statistics, 2003). (Births to fathers over 54 years account for less than $0.5 \%$ of live births within marriages and are not shown.) Reproduced with permission from Ref. 4.

fertilization and pregnancy rates. Dain et al. ${ }^{18}$ found in their review that except for an age-dependent decrease in semen volume, other parameters such as concentration, motility and morphology, were not found to decrease with advancing age.

Moreover, they have found no correlation between advanced paternal age and rates of fertilization, implantation, pregnancy, miscarriage and live birth in IVF (Table 1). ${ }^{18-28}$ Although embryo quality at the cleavage stage (days 2-3) was not affected by increasing males' age, it was associated with a significant decrease in blastocyst embryo formation, probably reflecting male genomic activation within the embryo.

\section{CHROMOSOMAL ABNORMALITIES}

Aneuploidy accounts for $30 \%-50 \%$ of all pregnancies. Most are lethal and found in fetal material from miscarriage. Aneuploidy arises mostly from non-disjunction during meiosis (MI+MII). ${ }^{29,30}$ The 45,X0 monosomy and trisomies of 16, 21 and 22 chromosomes comprise $60 \%$ of aneuploidy in pregnancy loss. Trisomies of chromosomes 13 , 18 and 21, and sex chromosome can reach birth ( $0.3 \%$ of all births). Most autosomal trisomies arise from maternal origin. ${ }^{31}$ The influence of paternal age on the incidence of Down syndrome (DS) is controversial. Most studies have not found paternal effect on the incidence of trisomy 21 and several other aneuploidies. Analysis of 352 cases of $\mathrm{DS}^{31}$ has found that only $9.1 \%$ of cases derived from paternal origin. The risk of DS among offspring of aged fathers is low. No clear association between fathers' age ( $>50$ years) and the occurrence of DS or several other chromosomal aneuploidies was found. ${ }^{32}$ In contrast, very young fathers (age $<20$ years) were found to be at increase risks for the occurrence of DS and trisomy 22 (relative risk=4), oral clefts, neural tube disease, cystic kidney and hypospadias, when compared to 25 - to 29 -year-old fathers. ${ }^{33}$ This study was limited by a small number of cases and difficulties separating maternal and paternal age effects. Sex chromosome aneuploidies are the most common abnormalities in live birth. Around $55 \%$ of the cases derive from paternal origin $(80 \%$ of monosomy $45, \mathrm{X} 0,6 \%$ of $47, \mathrm{XXX}, 100 \%$ of $47, \mathrm{XYY}$ and $50 \%$ of Klinefelter syndrome $(47, \mathrm{XXY})) .{ }^{34}$ No clear association was found between older fathers' age ( $>50$ years) and XY chromosomes aneuploidy. There is no information regarding males' age and 47,XXX/ $47, \mathrm{XYY}$. This is due to a paucity of data available on affected offspring (most abnormal embryos are lost) and difficulties in separating the maternal and paternal contributions.

\section{Sperm chromosomal anomalies}

The genetic material in the mature sperm nucleus is highly condensed. First chromosomal information derived from the human sperm/hamster egg method, came from zona pellucida-denuded hamster eggs inseminated by human sperm. ${ }^{35}$ Method limitations included high price, time consumption, the need for intensive labor, paucity of spermatozoa available for analysis, the need for fertile men only (only ejaculated sperm) and the inability to distinguish between diploid sperm and dispermy. In a study which included seven men aged 5974 years and five men aged 23-39 years, Sartorelli et al. ${ }^{36}$ have found that the frequency of numerical and structural chromosomal aberrations (acentric fragments and complex radial figures) was significantly

Table 1 The effect of paternal age on assisted reproduction outcome (reproduced with permission from Ref. 18)

\begin{tabular}{|c|c|c|c|c|c|c|}
\hline Reference & Fertilization & Implantation & Embryo quality & Pregnancy rate & $\begin{array}{l}\text { Pregnancy } \\
\text { loss rate }\end{array}$ & $\begin{array}{l}\text { Liveborn } \\
\text { deliveries }\end{array}$ \\
\hline Ferreira et al. ${ }^{19}$ & - & $\begin{array}{l}\text { Decrease only in } \\
\text { oligozoospermic }\end{array}$ & Days 2-3 (NS) & $\begin{array}{l}\text { Decrease only in } \\
\text { oligozoospermic }\end{array}$ & NS & - \\
\hline Aboulghar et al. ${ }^{20}$ & Decrease & - & Days 2-3 (NS) & NS & - & - \\
\hline Paulson et al. ${ }^{21}$ & NS & - & - & NS & - & NS \\
\hline Bellver et $a .^{22}$ & NS & NS & Days 2-3 (NS) & NS & NS & - \\
\hline Spandorfer et al. ${ }^{23}$ & NS & NS & Increase in digynity & NS & NS & NS \\
\hline Frattarelli et al. ${ }^{24}$ & NS & NS & $\begin{array}{l}\text { Days } 2-3 \text { NS, decrease } \\
\text { at day } 5\end{array}$ & NS & Increase & Decrease \\
\hline de la Rochebrochard et al. ${ }^{25}$ & - & - & - & Decrease & - & - \\
\hline Luna et al. ${ }^{26}$ & Decline in IVF $>60$ years & Decline in men $>60$ years & $\begin{array}{l}\text { Decrease at days } 3,5 \\
\text { and } 6\end{array}$ & NS & NS & - \\
\hline Klonoff-Cohen and Natarajan ${ }^{27}$ & NS & - & - & Decrease & NS & Decrease \\
\hline Gallardo et al. ${ }^{28}$ & NS & NS & NS & NS & NS & - \\
\hline
\end{tabular}

Abbreviations: IVF, in vitro fertilization; NS, non-significant. 
greater $(P=0.02)$ in chromosomes of older donors when compared with those of the younger group. There is no consensus on the relationship between males' age and aneouploidy in spermatozoa. Buwe et al. ${ }^{37}$ used human fluorescence in situ hybridization (FISH) karyotyping, which allows simultaneous analysis of several chromosomes in a shorter time. In addition, analysis can be made using a very low number of sperm cells, including samples retrieved from the genital tract or directly from the testicular tissue. ${ }^{38,39}$ Limitations of the method are probe specificity and the inability to distinguish between absence of signal due to hybridization failure and nullisomy. Age studies have yielded no evidence for an age-related increase in sperm disomy frequencies. These methods (FISH and sperm/ hamster egg) demonstrated an increased rate of aneuploid sperm among infertile men, compared to fertile population, ${ }^{40}$ even when somatic karyotype is normal. Meiotic studies demonstrated that infertile men have impaired chromosome synapsis, decreased frequency of recombination and increased frequency of chromosomes completely lacking a recombination site, errors rendering cells to meiotic arrest and production of aneuploid gametes. ${ }^{40}$

Sex and autosomal chromosomal aneuploidy. Y chromosome is unique as it does not have an equal partner for pairing in male meiosis. Sex chromosome non-disjunction in meiosis I results in XY sperm whereas in meiosis II it forms XX/YY sperm. Evidence was found for an age-related increase in XY sperm disomy with advanced donor age (36-60 years compared with $18-35$ years). ${ }^{32,37}$ In addition, there is a more pronounced age-related effect on XX/YY disomy rate, a two- to three-fold higher frequency being seen when sperm originate from men of over 50 years. Dakouane et al. ${ }^{41}$ have examined testicular biopsies from 36 older men (61-102 years old) and 10 younger men (29-40 years old) by histomorphometry and FISH (X, Y and 18 chromosomes). The rate of aneuploidy in older subjects (61-95 years old) with preserved spermatogenesis was not different from that found in the control group and was increased in older subjects with altered or impaired spermatogenesis. Triploidy is one of the most frequent chromosomal aberrations $(\sim 1 \%)$. It is usually associated with an early abortion. Diandric (paternal) triploids, originate from dispermy, whereas digynic (maternal) triploids originate from errors in meiosis II. ${ }^{42}$ However, data are lacking in regard to the effect of paternal age on the incidence of triploidy.

\section{Structural chromosomal anomalies in sperm analysis}

Structural chromosomal anomalies comprise $0.25 \%$ of births, $0.4 \%$ of stillbirths and $2 \%$ of abortions. Population-based studies did not find evidence for an increased rate with advancing paternal age (fetuses and abortions). ${ }^{42}$ Around $80 \%$ of the de novo cases (partial deletions) originate in male germ line. Their frequency in men with normal sperm varies from $7 \%$ to $14 \%$. Cytogenetic studies are rare. Despite of predominance of paternal origin, a significant influence of paternal age has not been demonstrated. Using sperm FISH analysis to demonstrate centromeric and subtelomeric regions, a significant association with donors' age was detected for the frequency of acentric fragments of chromosome $1(P<0.05) .{ }^{43}$ Sloter et al. ${ }^{44}$ have found that frequency of sperm with segmental duplications and deletions of chromosome 1 was twice among older men, and frequency of sperm carrying breaks within the 1q12 fragile site region nearly doubled.

\section{Telomeres and paternal age}

Telomeres are repetitive linear DNA sequences, 3-17 kb long, located at the ends of chromosomes, protecting them from deterioration, clumping, fusion with neighboring chromosomes and DNA breaks. During cell division, enzymes that duplicate DNA cannot continue their duplication all the way to the end of the chromosome. Therefore, telomere regions deter degradation of genes near the ends of chromosomes by allowing for the shortening of chromosome ends, thereby acting as disposable buffers that blocking chromosomal ends. During each cell division, telomeres shorten and are replenished by the enzyme telomerase reverse transcriptase. After a critical number of cell divisions when telomere length (TL) shortens considerably, this marks the termination of proliferation stops. ${ }^{45}$ Cells may enter apoptosis. ${ }^{46,47}$ Males lose telomere sequence relatively faster than females ( $31 \mathrm{bp}$ year ${ }^{-1}$ vs. $14 \mathrm{bp} \mathrm{year}^{-1}$ ) and the rate of telomere loss slows throughout lifespan. TL is linked to ageassociated diseases, when shorter TL increases the risk of mortality due to infection or heart disease, and has recently been regarded as a biological marker for aging. ${ }^{48,49}$ Evidence was found for fatheroffspring heritage of TL. ${ }^{50,51}$ This correlation diminishes with increasing age, suggesting that non-inheritable factors have an impact on TL during life. ${ }^{52}$ Increasing TL was found in offspring of advanced paternal age $\left(\sim 17\right.$ bp year $\left.^{-1}\right) .{ }^{47}$ This implies that TL is not completely reset in the zygote. Implications of TL on health are unknown. For every additional year of paternal age, TL in offspring increased at a magnitude ranging for half to more than twice of the annual attrition in TL with age. ${ }^{53}$ Sperm TL analyses were compatible with the emergence in older men of a subset of sperm with elongated telomeres. ${ }^{53}$ One of the hypotheses for this phenomenon is that this paternal effect is an adaptive signal of the expected age of male reproduction in the environment where offspring are born into. The offspring of lineage of older fathers will tend to have longer telomeres better preparing them for an environment with higher expected age at reproduction. ${ }^{47}$

\section{Spontaneous abortions}

A case-control study of 13865 women found that increasing paternal age is significantly associated with spontaneous abortion, independent of maternal age and multiple other factors. ${ }^{54}$ Slama et al. ${ }^{55}$ observed that the risk of spontaneous abortion was almost twice higher among men aged $>45$ years than among those aged $<25$ years. Paternal age of $>40$ years becomes relevant concerning miscarriages when the woman was $>30$ years old. ${ }^{56}$

\section{AUTOSOMAL DOMINANT (AD) DISEASES}

\section{Mutation at fibroblast growth factor receptor 3 (FGFR3)}

Until 1975, four AD diseases were related to pure paternal age effect: achondroplasia $(\mathrm{ACH})$, Apert syndrome, myositis ossificans and Marfan syndrome. ${ }^{57}$ The average age of fathers at the time of birth of an affected child was 6.1 years older than that of fathers of normal children in the same population, whereas maternal age and birth order showed no significant effect. In 1976, Francke et al. ${ }^{58}$ studied five families in which the Lesch-Nyhan mutation appeared first in a heterozygous mother. The mean age of maternal grandfathers at the birth of a daughter was about 7.3 years older than the population mean, and though numbers were small, they could suggest an age-related paternal effect on X-linked recessive disorders. ${ }^{58} \mathrm{ACH}$ was the first genetic disorder that hypothesized to have paternal age influence. ${ }^{59} \mathrm{ACH}$ is the most common form of skeletal dysplasia characterized by disproportionately short stature, lumbar lordosis and relative macrocephaly with incidence of $1: 25000$ live births. ${ }^{60}$ It is caused by mutations in FGFR3 gene. A predominant FGFR3 mutation, G to A transition at nucleotide 1138, has been found in more than $98 \%$ of the affected 
individuals from different ethnic groups .A second mutation described in about $2 \%$ of $\mathrm{ACH}$ patients is $\mathrm{G}$ to $\mathrm{C}$ transversion at the same codon. The mutation causes an arrest of chondrocyte terminal differentiation and a blockade of bone elongation and growth. Affected individuals have shorter life expectancy due to accidental, neurological and heart disease-related deaths. Heart disease-related mortality between ages of 25 and 35 years, was more than 10 times higher than the general population. Overall survival and the average life expectancy for this ACH population were decreased by 10 years. ${ }^{50}$ Dakouane Giudicelli et $a l^{61}$ examined sperm cells from ejaculate and testicular biopsies. They have found that the rate of G1138A mutation did not significantly vary with age in sperm, whereas in testis biopsies, it increased markedly past the age of 70 years. They have also identified a mosaic for this mutation which was detected in the testis of three subjects who were $>80$ years of age. The association between paternal age and incidence of ACH has been also reported by Orioli et al. ${ }^{62}$ Mean paternal age was highly elevated in $\mathrm{ACH}$. Approximately $50 \%$ of $\mathrm{ACH}$ patients were born to fathers above the age of 35 years. All sporadic ACH cases have been found to inherit the G1138A mutations from their fathers. This association was also found by Wyrobek et al. ${ }^{63}$ The paternal age effect has been attributed to spermatogonial replication errors that accumulate with increased age. Mutations in FGFR3 gene cause other different disorders of skeletal dysplasias, including hypochondroplasia and thanatophoric dysplasia (which is lethal). The pattern of increase of these mutations with paternal age is exponential. ${ }^{61}$ Tiemann-Boege et al. ${ }^{64}$ have determined the frequency of the nucleotide substitution in the fibroblast growth factor FGFR3 gene that causes ACH. They have found that the age-related increase of the mutation for $\mathrm{ACH}$ in sperm is lower than expected and does not explain the exponential increase of the disease with paternal age. They have proposed a number of alternatives mechanisms which may explain this discrepancy, including selection for sperm that carry the mutation or an age-dependent increase in premutagenic lesions that remain unrepaired in sperm and are inefficiently detected by the PCR assay.

\section{Mutations in the FGFR2 gene}

Crouzon syndrome, Apert syndrome and Pfeiffer syndrome are all $\mathrm{AD}$ craniosynostotic disorders that can be caused by mutations in the FGFR2 gene. ${ }^{65}$ The frequency of new mutations, responsible for craniosynostosis syndromes is estimated as 1:65000 live births. Most Apert syndrome cases result from one of two site (C755G and $\mathrm{C} 758 \mathrm{G}$ ) mutations in the fibroblast FGFR2 occurring in a normal father's germ line. Eleven different mutations that are responsible for sporadic cases of either Crouzon syndrome or Pfeiffer syndrome also arise in the paternal germ line. All mutations were associated with increased paternal age and molecularly proved to be a paternal origin of mutation. ${ }^{66,67}$ Glaser et al. ${ }^{68}$ have found that two nucleotide substitutions in the human FGFR2 gene (C755G or $C 758 G$ ) are responsible for virtually all sporadic cases of Apert syndrome. This condition is $100-1000$ times more common than that genomic mutation frequency data predict. Choi et al. ${ }^{69}$ have performed testis analysis of the FGFR2 mutation of Apert syndrome in four individual testes from three older individuals (45, 54 and 62 years) and two testes from younger donors (23 and 19 years). Each testis was dissected into 192 pieces. They demonstrated that spontaneous mutations are not uniformly distributed throughout normal testes. Instead, they have found foci where mutation frequencies were 3-4 orders of magnitude greater than the remaining tissue. They concluded that the nucleotide site was not a mutation hot spot. An alternative explanation for such foci involves positive selection acting on adult self-renewing spermatogonia experiencing the rare mutation which could not be rejected. Further, the two youngest individuals studied (19 and 23 years old) had lower mutation frequencies and smaller foci at both mutation sites compared with the older individuals. This implies that the mutation frequency of foci increases with age, and thus, selection could explain the paternal age effect for Apert syndrome and other genetic conditions. Based on their genetic analysis of human sperm, Goriely et al. ${ }^{70}$ proposed that specific FGFR2 mutations are positively selected in sperm because they encode proteins with gain-of-function properties, favoring clonal expansion of mutant spermatogonial cells. Among FGFR2 mutations, those causing Apert syndrome may be especially prevalent because they enhance signaling by fibroblast growth factor ligands specific for each of the major expressed isoforms. More than 10 genetic disorders are associated with advanced paternal age; half of them (Apert syndrome, $\mathrm{ACH}$, multiple endocrine neoplasia type $2 \mathrm{~B},{ }^{71}$ Crouzon syndrome and Pfeiffer syndrome) have definitively been shown to be the result of mutations that are paternal in origin. The mean paternal age at birth of 80 mutant cases of dominant osteogenesis imperfecta was significantly higher than that of population controls and remained so after adjusting for maternal age. ${ }^{72}$ The weak paternal age effect in neurofibromatosis may be due to the fact that new mutations are not base substitutions. The overall risk calculation for $\mathrm{AD}$ diseases $(0.3 \%-0.5 \%$ among offspring of fathers aged $>40$ years $)^{73}$ may have been overestimated. The calculation was based on the assumption that the paternal age effect found in $\mathrm{ACH}$ is typical of all $\mathrm{AD}$ diseases, an assumption which was not accurate. Prenatal screening for paternally transmitted AD disease is not yet recommended routinely. Penrose ${ }^{59}$ has proposed the concept of 'copy error hypothesis': in males, germ cells (spermatogonia) divide continuously and undergo many more mitotic replications than oogonias. The higher number of germ cell replications among males compared with females (oogonia-21 replications until the stage of oocyte; spermatogonia-30 replications until puberty and then 23 replications every year) may serve as an explanation for the increased rate of paternally-inherited point mutations compared with maternal inheritance. ${ }^{74}$ One explanation for this could be that the efficiency of the proofreading of the replication machinery (DNA repair mechanism) in spermatogenesis declines with age ${ }^{75}$ due to endogenous (oxidative stress) or exogenous mutagenic damage. This is due to the absence of DNA repair mechanism in late spermatids, immature and mature spermatozoa, ${ }^{76,77}$ and the reduced levels of antioxidant enzymes in seminal plasma of older men, ${ }^{78}$ a finding which is in concordance with the age-dependent decrease in oxidative potential of seminal plasma ${ }^{17}$ (Lissak et al, 2004, unpublished data).

\section{Birth defects}

Non-Mendelian disease characters may depend on two, three or more genetic loci. In addition, contributions from environmental factors, nutrition during organogenesis and exposure to chemicals may be involved. These multifactorial conditions include the common birth defects (cleft palate, congenital dislocation of the hip, congenital heart disease, etc.), behavioral traits such as IQ test performance or mental diseases such as schizophrenia. Yang et al. ${ }^{79}$ have performed a population-based retrospective cohort study of 5213248 subjects from the 1999-2000 birth registration data of the United States of America. They included 22 categories of birth defects and divided parental age into eight standard 5-year-old age groups: I, <20 years; II, 20-24 years; III, 25-29 years; IV, 30-34 years; V, 35-39 years; VI, 40-44 years; VII, 45-49 years; and VIII, 
$>50$ years. The overall prevalence of ascertained serious birth defects in the United States of America during 1999-2000 reported was $1.5 \%$. A progressively elevated risk of birth defects was observed with a $15 \%$ increase risk in the age group of 50 years old. Advanced maternal age was associated with a progressively elevated risk of birth defects with a 2.2-fold higher risk in the age group of 45 years old. The adjusted odds ratios (ORs) were 1.04, 1.08, 1.08 and 1.15, respectively, for infants born to fathers 30-35, 40-44, 45-49 and over 50 years (test for trend, $P=0.0155$ ), when compared with those infants born to fathers aged 25-29 years for any birth defect. Advanced paternal age was associated with increased risks of heart defects, tracheo-oesophageal fistula, esophageal atresia, other musculoskeletal/integumental anomalies, DS and other chromosomal anomalies. Fathers under 25 years of age were also at increased risks of spina bifida/meningocele, microcephalus, omphalocele/ gastroschisis and other musculoskeletal/integumental anomalies. Younger fathers were at increased risks of spina bifida/meningocele, microcephalus omphalocele/gastroschisis. However, results could be explained by associated maternal risk factors: smoking, alcohol and folic acid. Kazaura et al. ${ }^{80}$ investigated 1869388 births from The Medical Birth Registry of Norway. There was little evidence of increased risks by high paternal age for any category of defects, except for a category of 'other central nervous system' where risk estimates were 2.5 -fold (95\% confidence interval: 1.2-5.5) for fathers aged between 45 and 49 years compared with the reference age group (25-29 years). The risk of neural tube defects was 1.3 -fold $(95 \%$ confidence interval: 1.1-1.5) when the father's age was between 20 and 24 years relative to the reference. A pattern of moderately higher risks for younger fathers was consistent for anencephaly and spina bifida. An increased risk of heart defects was also estimated among children of young fathers. Zhu et al. ${ }^{81}$ investigated the Danish fertility database ( $n=71937$ ) between 1980 and 1996. Advanced paternal age ( $>40$ years) may be associated with an excess occurrence of some specific malformations (syndromes of multiple systems and malformations of extremities. Green et al., ${ }^{82}$ using the 1997-2004 data from the National Birth Defects Prevention Study, have found elevated ORs for each year increase in paternal age for cleft palate $(\mathrm{OR}=1.02)$, diaphragmatic hernia $(\mathrm{OR}=1.04)$, right ventricular outflow tract obstruction $(\mathrm{OR}=1.03)$ and pulmonary valve stenosis $(\mathrm{OR}=1.02)$. At younger paternal ages, each year increase in paternal age correlated with increased odds of having offspring with encephalocele, cataract, esophageal atresia, anomalous pulmonary venous return and coarctation of the aorta, but these increased odds were not observed at older paternal ages. The effect of paternal age was modified by maternal age for gastroschisis, omphalocele, spina bifida, all oro-facial clefts and septal heart defects.

Perinatal outcome. Nybo Andersen et al. ${ }^{83}$ examined 23821 pregnant women recruited consecutively to the Danish National Birth Cohort from 1997 to 1999 to assess the association between paternal age and fetal death. Pregnancies fathered by men aged 50 or more years $(n=124)$ had almost twice the risk of ending in a fetal loss compared with pregnancies with younger fathers (hazard ratio $=1.88$; $95 \%$ confidence interval: 0.93-3.82), after adjustment for maternal age, reproductive history and maternal lifestyle during pregnancy. Chen et al. ${ }^{84}$ have performed a retrospective cohort study of 2614966 live singletons born to women aged 20-29 years and estimated the independent effect of paternal age on adverse birth outcome. Teenagers $(<20$ years old $)$ had an increased risk of low birth weight $(\mathrm{OR}=1.13)$ preterm birth $(\mathrm{OR}=1.15)$, small-for-gestational-age births $(\mathrm{OR}=1.17)$, low Apgar score $(\mathrm{OR}=1.13)$, neonatal mortality $(\mathrm{OR}=1.22)$ and postneonatal mortality $(\mathrm{OR}=1.41)$. In contrast, advanced paternal age $(>40$ years) was not associated with the risk of adverse birth outcomes.

\section{NEUROCOGNITIVE DISORDERS}

\section{Autism}

Autism spectrum disorder (ASD) refers to a syndrome of social communication deficits and repetitive behaviors or restrictive interests. ${ }^{85}$ In an historical population-based cohort study on 132271 males, Reichenberg et al. ${ }^{86}$ have found a significant monotonic association between advanced paternal age and the risk of ASD. Offspring of men aged 40 years or older were 5.75 times $(P<0.001)$ more likely to have ASD compared with offspring of men younger than 30 years. BuizerVoskamp et al. ${ }^{87}$ examined the Dutch registry using 14231 patients and 56924 matched controls. ASD was significantly associated with increased paternal age. Older fathers ( $>40$ years of age) have 3.3 times increased odds of having a child with ASD compared to young fathers $(<20$ years of age). In sporadic cases of ASD, mutations in transcription factors which regulate the expression of genes associated with neurodevelopmental disorders may play a causal role. Alter et al. ${ }^{88}$ have used micro-arrays to measure the expression levels of $\geqslant 47000$ transcripts including 38500 well-characterized human genes in RNA from lymphocytes from each of 82 children with autism and 64 control subjects. A decrease in the variance in the distribution of gene expression levels in lymphocytes was associated with the diagnosis of autism and increased paternal age. Gene expression pathways involved in transcriptional regulation were found to be downregulated in the blood of children with autism and children of older fathers. These results may suggest a possible mechanism for decreased variance in gene expression in the etiology of paternal age-dependent autism.

\section{Schizophrenia}

Sipos et al. ${ }^{89}$ have conducted a population-based cohort study in Sweden. They have found that advanced paternal age was associated with schizophrenia, and the results were independent from sociodemographic or socioeconomic parameters, family history or early parental death. Meta-analysis of paternal age and schizophrenia risk in male vs. female offspring made by Miller et al. ${ }^{90}$ revealed that relative risk in the oldest fathers ( $\geqslant 50$ years) was 1.66 compared with younger fathers. The population attributable risk percentage was $10 \%$ for paternal age of $>30$ years and $5 \%$ for paternal age of $<25$ years. Buizer-Voskamp et al. ${ }^{87}$ have found that schizophrenia had significant associations for fathers aged $>35$ years $(\mathrm{OR}=1.27)$. Lee et al. ${ }^{91}$ have identified distinct characteristics of paternal age-related schizophrenia patients in regard to other schizophrenia patients (a discrepancy between verbal and performance intelligence and an early age of onset among females). The results of these studies support the theory that accumulating de novo mutations in the germ cells of older fathers might contribute to an increased risk of schizophrenia in their offspring. Point mutations are well known to increase with advancing paternal age ${ }^{92,93}$ while other errors such as an increased allele length mutation rate ${ }^{94}$ and chromosome breakage ${ }^{95}$ have in some cases also been associated with advanced paternal age.

\section{Bipolar disorder}

Offspring of men aged 55 years and older were 1.37 times more likely to be diagnosed as having bipolar disorder than the offspring of men aged 20-24 years. ${ }^{96}$ In contrast, Buizer-Voskamp et al. ${ }^{87}$ have not found any association between paternal age and bipolar disorder, but have found that for major depressive disorder, both younger and older fathers had increased odds. 


\section{Neurocognitive development}

Saha et al. $^{97}$ have examined a sample of singleton children $(n=33437)$ from the US Collaborative Perinatal Project. Outcome measures were assessed at 8 months, 4 years and 7 years (Bayley scales, Stanford Binet Intelligence Scale, Graham-Ernhart Block Sort Test, Wechsler Intelligence Scale for Children and Wide Range Achievement Test). Advanced paternal age showed significant associations with poorer scores on all of the neurocognitive measures apart from the Bayley Motor score. The findings were broadly consistent in direction and effect size at all three ages. Malaspina et al..$^{98}$ examined the association of paternal age and IQ scores, using the Israeli Army Board data on 44175 individuals from a richly described birth cohort, along with maternal age and other potential modifiers. A significant inverted U-shaped relationship was observed between paternal age and IQ scores, which was independent from a similar association of IQ scores with maternal age. These relationships were not significantly attenuated by controlling for multiple possible confounding factors. Overall, parental age accounted for approximately $2 \%$ of the total variance in IQ scores, with later paternal age lowering non-verbal IQ scores more than verbal IQ scores. Vestergaard et al., ${ }^{99}$ in a population-based cohort study of 96654 children, found that fathers aged 35 years or older were slightly more likely to have a child diagnosed with epilepsy compared to fathers aged 25-29 years.

\section{OTHER CONDITIONS}

Yip et al. ${ }^{100}$ have examined a population of 4.3 million children $(\leqslant 14$ years old) with their parents, born between 1961 and 2000. Paternal age was significantly associated with leukaemia (oldest age group's incidence rate ration $=1.31$ ). For central nervous system cancer, the effect of paternal age was found to be significant (oldest age group's relative risk $=1.69$ ) when maternal age was included in the analysis. Weiss-Salz et al. ${ }^{101}$ have found an association of paternal age at birth and the risk of breast cancer under the age of 40 years in offspring. Choi et al. ${ }^{102}$ have found that the risk of breast cancer significantly increased as the paternal age increased $(P$ (for trend $)=0.025)$. The association was stronger after controlling for maternal age. Women whose fathers were aged $\geqslant 40$ years at their birth had a 1.6-fold increased risk of breast cancer compared with fathers aged $<30$ years. This association was profound in breast cancer cases in premenopausal women $(\mathrm{OR}=1.9$ for paternal aged $\geqslant 40$ years $v s .<30$ years $)(P$ (for trend $)=0.031$ ). In a retrospective analysis using the Swedish Inpatient Register, Montgomery et al. ${ }^{103}$ identified 4443 patients with a diagnosis of multiple sclerosis. Twenty-four thousand, one hundred and ninety-four controls were selected with similar characteristics for year, county of birth and survival until at least the age at diagnosis of the matched cases. The risk of multiple sclerosis increased steadily with fathers' age but not mothers' age, up to 2.00 (1.35-2.96) for 51- to 55-year-old fathers (compared with 21- to 25-year-old fathers).

\section{Epigenetics}

The non-genomic pathway of inheritance, otherwise known as epigenetics (which involves the methylation or acetylation of DNA or histones as a mechanism modulating gene transcription and expression), has recently gained intensive scientific attention due to its possible role in experience- dependent mother-infant influence. Since epigenetic patterns are only metastable and may be changed by environmental as well as endogenous factors, this may serve as an alternative mechanism by which age-related changes in parental epigenetic 'footprints' may affect the phenotype of their offspring, regarding the susceptibility to certain diseases. Adkins et al. ${ }^{104}$ have used a genome-wide survey of 27578 cytosine guanine dinucleotides in a cohort of 168 newborns. They examined the association between DNA methylation in newborns and parents, and newborn traits. They have found that the methylation level of 144 cytosine guanines in 142 genes was correlated with maternal age. A weaker correlation was observed with paternal age. The end products of these genes involved glucose/carbohydrate metabolism, neurological regulation, processes related to cancer, nucleocytoplasmic transport and transcriptional regulation. They concluded that congenital differences in cytosine guanine methylation are associated with parental age and may contribute to future risk of certain diseases. Perrin et al. ${ }^{105}$ and Sipos et al. ${ }^{89}$ have raised the question whether epigenetic changes that occur as paternal age advances, may be casually related to the susceptibility of schizophrenia. Errors in epigenetic processes, such as parental imprinting may possibly have serious effects on offspring both pre- and postnataly and into adulthood. Interestingly, paternal exposure to toxicant and nutritional state as well as age, have been found to influence not only offspring but sometimes grand-offspring. ${ }^{106}$

\section{SUMMARY}

In Western societies, advanced paternal age is a phenomenon that parallels advanced maternal age and is associated with various reproductive hazards. Testicular function and sperm parameters deteriorate rather gradually with advanced age. However, unlike in the female, assisted reproductive techniques such as IVF-intracytoplasmic sperm injection, may circumvent these obstacles and enable fertilization in cases with severe male factor infertility, otherwise unlikely to conceive.

In view of the rise in late parenthood combined with these powerful techniques, it is inevitable that other aspects may emerge regarding late parenthood and be expressed in the offspring.

There is an increased age-associated risk of sperm germ line mutations and specific genetic disorders, specifically AD type.

Epigenetic imprinting which alters levels of gene transcription, may contribute to the susceptibility of offspring of old men to diseases of multifactorial origin, including neurocognitive and psychiatric disorders, and even malignancy. Recent micro-array techniques reported a reduced variance in the distribution of gene expression levels, which was associated with autism and advanced paternal age.

Possible mechanisms may be prolonged periods of exposure to nutritional and environmental toxicants, an age-dependent decrease in anti-oxidant mechanisms and a positive selection of mutated spermatozoa, vulnerable to the accumulation of mutations due to their high rate of divisions.

Interestingly, the offspring of a lineage of older fathers will tend to have longer telomeres, which may imply better preparation for an environment with a higher expected age at reproduction.

Different evolutionary aspects are involved in the aged male father in humans. This may dictate a different approach to the impact of males' age on reproduction. Therefore, in view of the growing number of older patients attending fertility and assisted reproductive facilities, proper counseling about the implications of age effects on gamete quality should be provided to both partners prior to family planning and infertility treatment.

\section{COMPETING FINANCIAL INTERESTS}

The authors declare no competing financial interests.

1 Balasch J. Ageing and infertility: an overview. Gynecol Endocrinol2010; 26: 855-60.

2 Tatone C. Oocyte senescence: a firm link to age-related female subfertility. Gynecol Endocrinol 2008; 24: 59-63.

3 Kühnert B, Nieschlag E. Reproductive functions of the ageing male. Hum Reprod Update 2004; 10: 327-39. 
4 Bray I, Gunnell D, Davey Smith G. Advanced paternal age: how old is too old? J Epidemiol Community Health 2006; 60: 851-3.

5 Amann RP. The cycle of the seminiferous epithelium in humans: a need to revisit? J Androl 2008; 29: 469-87.

6 Handelsman DJ, Staraj S. Testicular size: the effects of aging, malnutrition, and illness. J Androl 1985; 6: 144-51.

7 Sampson N, Untergasser G, Plas E, Berger P. The ageing male reproductive tract. J Pathol 2007; 211: 206-18.

8 Harman SM, Metter EJ, Tobin JD, Pearson J, Blackman MR. Longitudinal effects of aging on serum total and free testosterone levels in healthy men. Baltimore Longitudinal Study of Aging. J Clin Endocrinol Metab 2001; 86: 724-31.

9 Mahmoud AM, Goemaere S, El-Garem Y, van Pottelbergh I, Comhaire FH et al. Testicular volume in relation to hormonal indices of gonadal function in communitydwelling elderly men. J Clin Endocrinol Metab 2003; 88: 179-84.

10 Baccarelli A, Morpurgo PS, Corsi A, Vaghi I, Fanelli M et al. Activin A serum levels and aging of the pituitary-gonadal axis: a cross-sectional study in middle-aged and elderly healthy subjects. Exp Gerontol 2001; 36: 1403-12.

11 Nieschlag E, Lammers U, Freischem CW, Langer K, Wickings EJ. Reproductive functions in young fathers and grandfathers. J Clin Endocrinol Metab 1982; 55: 676-81.

12 Amaral S, Ramalho-Santos J. Aging, mitochondria and male reproductive function. Curr Aging Sci 2009; 2: 165-73.

13 Mirone V, Ricci E, Gentile V, Basile Fasolo C, Parazzini F. Determinants of erectile dysfunction risk in a large series of Italian men attending andrology clinics. Eur Urol 2004; 45: 87-91.

14 Rolf C, Kenkel S, Nieschlag E. Age-related disease pattern in infertile men: increasing incidence of infections in older patients. Andrologia 2002; 34: 209-17.

15 Eskenazi B, Wyrobek AJ, Sloter E, Kidd SA, Moore L et al. The association of age and semen quality in healthy men. Hum Reprod 2003; 18: 447-54.

16 Sloter E, Schmid TE, Marchetti F, Eskenazi B, Nath J et al. Quantitative effects of male age on sperm motion. Hum Reprod 2006; 21: 2868-75.

17 Lissak A, Wiener-Megnazi Z, Reznick AZ, Shnizer S, Ishai D et al. Oxidative stress indices in seminal plasma, as measured by the thermochemiluminescence assay, correlate with sperm parameters. Fertil Steril 2004; 81 (Suppl 1): 792-7.

18 Dain L, Auslander R, Dirnfeld M. The effect of paternal age on assisted reproduction outcome. Fertil Steril 2011; 95: 1-8.

19 Ferreira RC, Braga DP, Bonetti TC, Pasqualotto FF, laconelli A Jr et al. Negative influence of paternal age on clinical intracytoplasmic sperm injection cycle outcomes in oligozoospermic patients. Fertil Steril 2010; 93: 1870-4.

20 Aboulghar M, Mansour R, Al-Inany H, Abou-Setta AM, Aboulghar M et al. Paternal age and outcome of intracytoplasmic sperm injection. Reprod Biomed Online 2007; 14: 588-92.

21 Paulson RJ, Milligan RC, Sokol RZ. The lack of influence of age on male fertility. Am J Obstet Gynecol 2001; 184: 818-22.

22 Bellver J, Garrido N, Remohí J, Pellicer A, Meseguer M. Influence of paternal age on assisted reproduction outcome. Reprod Biomed Online 2008; 17: 595-604.

23 Spandorfer SD, Avrech OM, Colombero LT, Palermo GD, Rosenwaks Z. Effect of parental age on fertilization and pregnancy characteristics in couples treated by intracytoplasmic sperm injection. Hum Reprod 1998; 13: 334-8.

24 Frattarelli JL, Miller KA, Miller BT, Elkind-Hirsch K, Scott RT Jr. Male age negatively impacts embryo development and reproductive outcome in donor oocyte ART cycles. Fertil Steril 2008; 90: 97-103.

25 de la Rochebrochard E, de Mouzon J, Thepot T, Thonneau F. Fathers over 40 and increased failure to conceive: the lessons of in vitro fertilization in France. Fertil Steril 2006; 80: 1420-4.

26 Luna M, Finkler E, Barritt J, Bar-Chama N, Sandler B et al. Paternal age and assisted reproductive technology outcome in ovum recipients. Fertil Steril2009; 92: 1772-5.

27 Klonoff-Cohen HS, Natarajan L. The effect of advancing paternal age onpregnancy and live birth rates in couples undergoing in vitro fertilization or gamete intrafallopian transfer. Am J Obstet Gynecol 2004; 191: 507-14.

28 Gallardo E, Simón C, Levy M, Guanes PP, Remohí J et al. Effect of age on sperm fertility potential: oocyte donation as a model. Fertil Steril 1996; 66: 260-4.

29 Hassold T, Hall H, Hunt P. The origin of human aneuploidy: where we have been, where we are going. Hum Mol Genet 2007; 16 (Spec no. 2): R203-8.

30 Suzumori N, Sugiura-Ogasawara M. Genetic factors as a cause of miscarriage. Curr Med Chem 2010; 17: 3431-7.

31 Zaragoza MV, Jacobs PA, James RS, Rogan P, Sherman S. Nondisjunction of human acrocentric chromosomes: studies of 432 trisomic fetuses and liveborns. Hum Genet 1994; 94: 411-7.

32 Sloter E, Nath J, Eskenazi B, Wyrobek AJ. Effects of male age on the frequencies of germinal and heritable chromosomal abnormalities in humans and rodents. Fertil Steril 2004; 81: 925-43.

33 McIntosh GC, Olshan AF, Baird PA. Paternal age and the risk of birth defects in offspring. Epidemiology 1995; 6: 282-8.

34 Tempest HG. Meiotic recombination errors, the origin of sperm aneuploidy and clinical recommendations. Syst Biol Reprod Med 2011; 57: 93-101.

35 Martin RH, Lin CC, Balkan W, Burns K. Direct chromosomal analysis of human spermatozoa: preliminary results from 18 normal men. Am J Hum Genet 1982; 34: 459-68.

36 Sartorelli EM, Mazzucatto LF, de Pina-Neto JM. Effect of paternal age on human sperm chromosomes. Fertil Steril 2001; 76: 1119-23.
37 Buwe A, Guttenbach M, Schmid M. Effect of paternal age on the frequency of cytogenetic abnormalities in human spermatozoa. Cytogenet Genome Res 2005 111: 213-28.

38 Wyrobek AJ, Schmid TE, Marchetti F. Cross-species sperm-FISH assays for chemical testing and assessing paternal risk for chromosomally abnormal pregnancies. Environ Mol Mutagen 2005; 45: 271-83.

39 Gianaroli L, Magli MC, Ferraretti AP. Sperm and blastomere aneuploidy detection in reproductive genetics and medicine. J Histochem Cytochem 2005; 53: 261-7.

40 Martin RH. Meiotic chromosome abnormalities in human spermatogenesis. Reprod Toxicol 2006; 22: 142-7.

41 Dakouane M, Bicchieray L, Bergere M, Albert M, Vialard F et al. A histomorphometric and cytogenetic study of testis from men 29-102 years old. Fertil Steril 2005; 83 923-8.

42 Zaragoza MV, Surti U, Redline RW, Millie E, Chakravarti A et al. Parental origin and phenotype of triploidy in spontaneous abortions: predominance of diandry and association with the partial hydatidiform mole. Am J Hum Genet2000; 66: 1807-20.

43 McInnes B, Rademaker A, Martin R. Donor age and the frequency of disomy for chromosomes 1, 13, 21 and structural abnormalities in human spermatozoa using multicolour fluorescence in-situ hybridization. Hum Reprod 1998; 13: 2489-94.

44 Sloter ED, Marchetti F, Eskenazi B, Weldon RH, Nath J et al. Frequency of human sperm carrying structural aberrations of chromosome 1 increases with advancing age. Fertil Steril 2007; 87: 1077-86.

45 Oeseburg H, de Boer RA, van Gilst WH, van der Harst P. Telomere biology in healthy aging and disease. Pflugers Arch 2010; 459: 259-68.

46 Martínez P, Blasco MA. Telomeric and extra-telomeric roles for telomerase and the telomere-binding proteins. Nat Rev Cancer 2011; 11: 161-76.

47 Eisenberg DT. An evolutionary review of human telomere biology: the thrifty telomere hypothesis and notes on potential adaptive paternal effects. Am J Hum Biol2011; 23: 149-67.

48 de Meyer T, Rietzschel ER, de Buyzere ML, de Bacquer D, van Criekinge W et al Asklepios investigators. Paternal age at birth is an important determinant of offspring telomere length. Hum Mol Genet 2007; 16: 3097-102.

49 Unryn BM, Cook LS, Riabowol KT. Paternal age is positively linked to telomere length of children. Aging Cell 2005; 4: 97-101.

50 Nordfjäll K, Larefalk A, Lindgren P, Holmberg D, Roos G. Telomere length and heredity: indications of paternal inheritance. Proc Natl Acad Sci USA 2005; 102 : 16374-8.

51 Njajou OT, Cawthon RM, Damcott CM, Wu SH, Ott S et al. Telomere length is paternally inherited and is associated with parental lifespan. Proc Natl Acad Sci USA 2007; 104: 12135-9.

52 Nordfjäll K, Svenson U, Norrback KF, Adolfsson R, Roos G. Large-scale parent-child comparison confirms a strong paternal influence on telomere length. Eur J Hum Genet 2010; 18: 385-9.

53 Kimura M, Cherkas LF, Kato BS, Demissie S, Hjelmborg JB et al. Offspring's leukocyte telomere length, paternal age, and telomere elongation in sperm. PLoS Genet 2008; 4: e37.

54 Kleinhaus K, Perrin M, Friedlander Y, Paltiel O, Malaspina D et al. Paternal age and spontaneous abortion. Obstet Gynecol 2006; 108: 369-77.

55 Slama R, Bouyer J, Windham G, Fenster L, Werwatz A et al. Influence of paternal age on the risk of spontaneous abortion. Am J Epidemiol 2005; 1: 816-23.

56 de la Rochebrochard E, Thonneau P. Paternal age and maternal age are risk factors for miscarriage; results of a multicentre European study. Hum Reprod 2002; 17: 1649 56

57 Jones KL, Smith DW, Harvey MA, Hall BD, Quan L. Older paternal age and fresh gene mutation: data on additional disorders. J Pediatr 1975; 86: 84-8.

58 Francke U, Felsenstein J, Gartler SM, Migeon BR, Dancis J et al. The occurrence of new mutants in the X-linked recessive Lesch-Nyhan disease. Am J Hum Genet 1976; 28: 123-37.

59 Penrose LS. Parental age and mutation. Lancet 1955; 269: 312-3.

60 Wynn J, King TM, Gambello MJ, Waller DK, Hecht JT. Mortality in achondroplasia study: a 42-year follow-up. Am J Med Genet A 2007; 143A: 2502-11.

61 Dakouane Giudicelli M, Serazin V, le Sciellour CR, Albert M, Selva J et al. Increased achondroplasia mutation frequency with advanced age and evidence for G1138A mosaicism in human testis biopsies. Fertil Steril 2008; 89: 1651-6.

62 Orioli IM, Castilla EE, Scarano G, Mastroiacovo P. Effect of paternal age in achondroplasia, thanatophoric dysplasia, and osteogenesis imperfecta. Am J Med Genet 1995; 59: 209-17.

63 Wyrobek AJ, Eskenazi B, Young S, Arnheim N, Tiemann-Boege I et al. Advancing age has differential effects on DNA damage, chromatin integrity, gene mutations, and aneuploidies in sperm. Proc Natl Acad Sci USA 2006; 103: 9601-6.

64 Tiemann-Boege I, Navidi W, Grewal R, Cohn D, Eskenazi B et al. The observed human sperm mutation frequency cannot explain the achondroplasia paternal age effect. Proc Natl Acad Sci USA 2002; 99: 14952-7.

65 Wilkie AO, Slaney SF, Oldridge M, Poole MD, Ashworth GJ et al. Apert syndrome results from localized mutations of FGFR2 and is allelic with Crouzon syndrome. Nat Genet 1995; 9: 165-72.

66 Tolarova MM, Harris JA, Ordway DE, Vargervik K. Birth prevalence, mutation rate, sex ratio, parents' age, and ethnicity in Apert syndrome. Am J Med Genet 1997; 72: 394-8.

67 Shotelersuk V, Mahatumarat C, Ittiwut C, Rojvachiranonda N, Srivuthana S et al. FGFR2 mutations among Thai children with Crouzon and Apert syndromes. J Craniofac Surg 2003; 14: 101-4. 
68 Glaser RL, Jiang W, Boyadjiev SA, Tran AK, Zachary AA et al. Paternal origin of FGFR2 mutations in sporadic cases of Crouzon syndrome and Pfeiffer syndrome. Am J Hum Genet 2000; 66: 768-77.

69 Choi SK, Yoon SR, Calabrese P, Arnheim N. A germ-line-selective advantage rather than an increased mutation rate can explain some unexpectedly common human disease mutations. Proc Natl Acad Sci USA 2008; 105: 10143-8.

70 Goriely A, McVean GA, van Pelt AM, O'Rourke AW, Wall SA et al. Gain-of-function amino acid substitutions drive positive selection of FGFR2 mutations in human spermatogonia. Proc Natl Acad Sci USA 2005; 102: 6051-6.

71 Carlson KM, Bracamontes J, Jackson CE, Clark R, Lacroix A et al. Parent-of-origin effects in multiple endocrine neoplasia type 2B. Am J Hum Genet 1994; 55: 1076 82.

72 Carothers AD, McAllion SJ, Paterson CR. Risk of dominant mutation in older fathers: evidence from osteogenesis imperfecta. J Med Genet 1986; 23: 227-30.

73 Friedman JM. Genetic disease in the offspring of older fathers. Obstet Gynecol 1981; 57: 745-9.

74 Tarín JJ, Brines J, Cano A. Long-term effects of delayed parenthood. Hum Reprod 1998; 13: 2371-6

75 Crow JF. The high spontaneous mutation rate: is it a health risk? Proc Natl Acad Sci USA 1997; 94: 8380-6.

76 Matsuda Y, Tobari I, Maemori M, Seki N. Mechanism of chromosome aberration induction in the mouse egg fertilized with sperm recovered from postmeiotic germ cells treated with methyl methanesulfonate. Mutat Res 1989; 214: 165-80.

77 Inoue M, Kurihara T, Yamashita M, Tatsumi K. Effects of treatment with methyl methanesulfonate during meiotic and postmeiotic stages and maturation of spermatozoa in mice. Mutat Res 1993; 294: 179-86.

78 Kelso KA, Redpath A, Noble RC, Speake BK. Lipid and antioxidant changes in spermatozoa and seminal plasma throughout the reproductive period of bulls. J Reprod Fertil 1997; 109: 1-6.

79 Yang Q, Wen SW, Leader A, Chen XK, Lipson J et al. Paternal age and birth defects: how strong is the association? Hum Reprod 2007; 22: 696-701.

80 Kazaura M, Lie RT, Skjaerven R. Paternal age and the risk of birth defects in Norway. Ann Epidemiol 2004; 14: 566-70.

81 Zhu JL, Madsen KM, Vestergaard M, Olesen AV, Basso 0 et al. Paternal age and congenital malformations. Hum Reprod 2005; 20: 3173-7.

82 Green RF, Devine O, Crider KS, Olney RS, Archer N et al: National Birth Defects Prevention Study. Association of paternal age and risk for major congenital anomalies from the National Birth Defects Prevention Study, 1997 to 2004. Ann Epidemiol 2010; 20: 241-9.

83 Nybo Andersen AM, Hansen KD, Andersen PK, Davey Smith G. Advanced paternal age and risk of fetal death: a cohort study. Am J Epidemiol 2004; 160: 1214-22.

84 Chen XK, Wen SW, Krewski D, Fleming N, Yang Q et al. Paternal age and adverse birth outcomes: teenager or 40+, who is at risk? Hum Reprod 2008; 23: 1290-6.

85 Anagnostou E, Taylor MJ. Review of neuroimaging in Autism spectrum disorders: what have we learned and where we go from here. Mol Autism 2011; 2: 4.

86 Reichenberg A, Gross R, Weiser M, Bresnahan M, Silverman J et al. Advancing paternal age and autism. Arch Gen Psychiatry 2006; 63: 1026-32.
87 Buizer-Voskamp JE, Laan W, Staal WG, Hennekam EA, Aukes MF et al. Paternal age and psychiatric disorders: findings from a Dutch population registry. Schizophr Res 2011; 129: 128-32.

88 Alter MD, Kharkar R, Ramsey KE, Craig DW, Melmed RD et al. Autism and increased paternal age related changes in global levels of gene expression regulation. PLoS One 2011; 6: e16715.

89 Sipos A, Rasmussen F, Harrison G, Tynelius P, Lewis G et al. Paternal age and schizophrenia: a population based cohort study. BMJ 2004; 329: 1070.

90 Miller B, Messias E, Miettunen J, Alaräisänen A, Järvelin MR et al. Meta-analysis of paternal age and schizophrenia risk in male versus female offspring. Schizophr Bull 2010; 37: 1039-47.

91 Lee $H$, Malaspina D, Ahn H, Perrin M, Opler MG et al. Paternal age related schizophrenia (PARS): latent subgroups detected by k-means clustering analysis. Schizophr Res 2011; 128: 143-9.

92 Crow JF. Spontaneous mutation in man. Mutat Res 1999; 437: 5-9.

93 Ellegren $\mathrm{H}$. Microsatellite mutations in the germline: implications for evolutionary inference. Trends Genet 2000; 16: 551-558.

94 Andreassen R, Lundsted J, Olaisen B. Mutation at minisatellite locus DYF155S1: allele length mutation rate is affected by age of progenitor. Electrophoresis 2002; 23: 2377-83.

95 Singh NP, Muller CH, Berger RE. Effects of age on DNA double-strand breaks and apoptosis in human sperm. Fertil Steril 2003; 80: 1420-30.

96 Frans EM, Sandin S, Reichenberg A, Lichtenstein P, Långström N et al. Advancing paternal age and bipolar disorder. Arch Gen Psychiatry 2008; 65: 1034-40.

97 Saha S, Barnett AG, Foldi C, Burne TH, Eyles DW et al. Advanced paternal age is associated with impaired neurocognitive outcomes during infancy and childhood. PLoS Med 2009; 6: e40.

98 Malaspina D, Reichenberg A, Weiser M, Fennig S, Davidson M et al. Paternal age and intelligence: implications for age-related genomic changes in male germ cells. Psychiatr Genet 2005; 15: 117-25.

99 Vestergaard M, Mork A, Madsen KM, Olsen J. Paternal age and epilepsy in the offspring. Eur J Epidemiol 2005; 20: 1003-5.

100 Yip BH, Pawitan Y, Czene K. Parental age and risk of childhood cancers: a populationbased cohort study from Sweden. Int J Epidemiol 2006; 35: 1495-503.

101 Weiss-Salz I, Harlap S, Friedlander Y, Kaduri L, Levy-Lahad E et al. Ethnic ancestry and increased paternal age are risk factors for breast cancer before the age of 40 years. Eur J Cancer Prev 2007; 16: 549-54.

102 Choi JY, Lee KM, Park SK, Noh DY, Ahn SH et al. Association of paternal age at birth and the risk of breast cancer in offspring: a case control study. BMC Cancer 2005; 5: 143.

103 Montgomery SM, Lambe M, Olsson T, Ekbom A. Parental age, family size, and risk of multiple sclerosis. Epidemiology 2004; 15: 717-23.

104 Adkins RM, Thomas F, Tylavsky FA, Krushkal J. Parental ages and levels of DNA methylation in the newborn are correlated. BMC Med Genet 2011; 12: 47.

105 Perrin M, Kleinhaus K, Messinger J, Malaspina D. Critical periods and the developmental origins of disease: an epigenetic perspective of schizophrenia. Ann NY Acad Sci 2010; 1204 Suppl: E8-13.

106 Curley JP, Mashoodh R, Champagne FA. Epigenetics and the origins of paternal effects. Horm Behav 2011; 59: 306-14. 